\title{
Efeito de oito semanas na potência de membros inferiores em atletas de voleibol feminino durante macrociclo de treinamento.
}

Caroline de A. Xavier $(I C)^{1}$, Aline C. Colares (PG) ${ }^{1}$, João $P$. Borin (PQ)

1 Grupo de Estudo em Teoria e Metodologia do Treinamento Desportivo - FÉF/UNICAMP

\section{Resumo}

A organização do treinamento desportivo torna-se fundamental em qualquer modalidade, pois a capacidade do músculo esquelético adaptar-se ao treinamento sistematizado é resultante de alterações tanto neuromusculares quanto metabólicas. Assim, o objetivo do presente trabalho foi analisar o efeito de oito semanas de treinamento na potência muscular de membros inferiores em atletas de voleibol durante o período preparatório. Participaram do estudo nove atletas e durante as oito semanas do período preparatório as voleibolistas foram avaliadas por meio do teste de salto vertical, utilizando a técnica de contramovimento (Counter Movement Jump).

Palavras Chave: Voleibol, Potencia de membros inferiores, Treinamento desportivo

\section{Introdução}

O Voleibol é uma modalidade que solicita dos atletas elevada quantidade de saltos repetitivos, em diversos movimentos como bloqueio, levantamento, saque e finalizações das jogadas ${ }^{1}$. Nesse sentido destaca-se a potencia muscular, considerada como uma capacidade dominante em jogadores de voleibol $^{2}$ e que deve treinada e avaliada periodicamente para controle e monitoramento do treinamento. Assim o objetivo do presente estudo foi analisar o efeito de oito semanas de treinamento na potência muscular de membros inferiores em atletas de voleibol durante o período preparatório. Participaram do estudo 9 atletas de voleibol da categoria juvenil e durante o período de treinamento foi avaliada a potencia muscular, por meio do salto vertical (Bosco et al, 1983) ${ }^{3}$, com a técnica de contramovimento (Counter Movement Jump), no início (M0) e ao final do período (M1). A distribuição da organização do treinamento é apresentada no gráfico 1. Após a coleta dos dados da potência, produziram-se informações no plano descritivo (média e desvio-padrão) e inferencial (teste $t$ de Student).

\section{Resultados e Discussão}

A partir dos dados coletados os principais resultados são apresentados nos gráficos 2 (Com auxílio dos membros superiores) e 3 (Sem auxílio dos membros superiores). Apesar de verificar sensível elevação, em ambos os testes, nota-se que não foram significativas $(p>0,05)$. Tais resultados são discutidos à luz da Ciência do Esporte considerando entre outros fatores: o conteúdo de treinamento aplicado, a adaptação das atletas às oito semanas de treinamento e o período preparatório de treinamento.

\section{Gráfico 1}

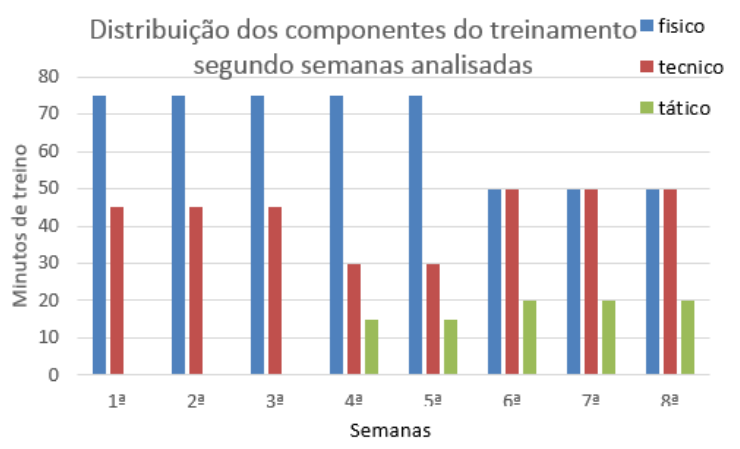

Gráfico 2

Gráfico 3
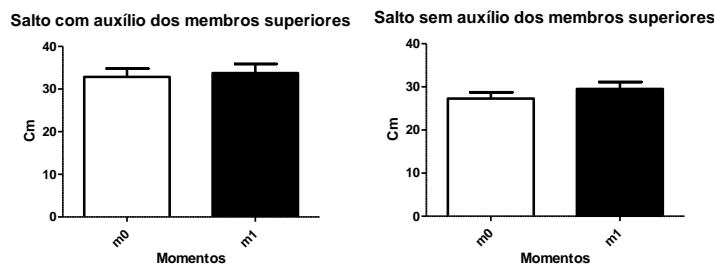

Conclusões

A partir dos resultados conclui-se que oito semanas de treinamento, no período preparatório, não foi suficiente para melhoria significativa da potencia dos membros inferiores em atletas de voleibol.

\section{Agradecimentos}

PIBIC, CNPq, FEF - Unicamp

\footnotetext{
CARDOSO J.R.; et al. Influência da utilização da órtese de tornozelo durante atividades do voleibol: avaliação eletromiográfica. Rev Bras Med Esporte. 11(5):276-280, 2005

2 BOMPA, T. O. A periodização no Treinamento Esportivo. Ed. Manole, $1^{a}$ ed., 2002

BOSCO, C.; LUHTANEN, P.; KOMI, P.V. A simple method for measurement of mechanical power in jumping. European Journal Applied Physiology Occup Physiol. Vol.50, No.2: p.273-82, 1983...
} 